\title{
Association between E469K polymorphism in the ICAM1 gene and the risk of diabetic nephropathy: a meta-analysis
}

\author{
Liya $\mathrm{Liu}^{1 \dagger}$, Dongling He${ }^{2 \dagger}$, Ling Fang ${ }^{3}$ and Xiaojie Yan $^{3^{*}}$
}

\begin{abstract}
Background: Inflammation may be a key pathophysiological mechanism in diabetic nephropathy (DN). Intercellular adhesion molecule 1 (ICAM1) is an acute phase marker of inflammation. ICAM1 rs5498 has been reported to be associated with the risk of DN. However, the previous findings were conflicting due to the limited sample sizes, different methodologies and ethnicities. Therefore, this study aimed to investigate the genetic association between ICAM1 rs5498 and the risk of DN.

Methods: Two investigators independently searched the studies from the databases PubMed, Web of Science, the Cochrane Library, Chinese National Knowledge Infrastructure (CNKI) and Embase. Pooled odds ratios (ORs) with 95\% confidence intervals (Cls) were used to assess the associations.

Results: No significant association was detected between ICAM1 rs5498 and DN susceptibility in allelic and recessive models $(p>0.05)$. However, significant reduction of frequencies of the dominant model of ICAM1 r55498 was only detected in the Caucasian subgroup $(\mathrm{OR}=0.80 ; 95 \% \mathrm{Cl}=[0.65,0.99], p=0.04)$ and type 1 diabetes mellitus subgroup $(\mathrm{OR}=0.80 ; 95 \% \mathrm{Cl}=[0.65,0.99], \mathrm{p}=0.04)$.

Conclusions: Thus, ICAM1 rs5498 might be a risk factor for DN in Caucasians and type 1 diabetes mellitus patients, which suggested that ICAM1 rs5498 might help in early diagnosis and prevention of this disease. Further studies were needed to clarify the biochemical function and pathological role of ICAM1 rs5498 in the risk of DN.
\end{abstract}

Keywords: Intercellular adhesion molecule 1 (ICAM1), Diabetic nephropathy (DN), Diabetes mellitus (DM), E469K

\section{Introduction}

Diabetes mellitus (DM) is a metabolic disorder associated with chronic micro and macro vascular complications $[1$, 2]. One of the worst chronic microvascular complication is diabetic nephropathy (DN) [3]. Approximately $40-45 \%$ of patients with type $1 \mathrm{DM}$ (T1DM) and $30 \%$ with type 2 DM (T2DM) develop DN $[4,5]$. DN is the most common single cause of end-stage renal disease (ESRD) [6]. The patients with DN exhibit persistent proteinuria, hypertension, declining renal function, and increased premature mortality, primarily as a result of cardiovascular disease

\footnotetext{
*Correspondence: yxi261314@163.com

${ }^{\dagger}$ Liya Liu and Dongling He contributed equally to this work.

${ }^{3}$ Department of Endocrinology, Shenzhen Hospital, Southern Medical

University, No. 1333, New Lake Road, Baoan District, Shenzhen 518000,

Guangdong, China

Full list of author information is available at the end of the article
}

[7]. Multi-factorial diseases including genetic and environmental factors are known to influence DM and DN $[8,9]$.

Genome-wide scans have predicted that genes located at chromosome 19p13 might be susceptible to T1DM [10]. The intercellular adhesion molecule 1 (ICAM1) gene is located in $19 \mathrm{p} 13$ and encodes a $90-\mathrm{kD}$ cell surface glycoprotein of the Ig super family involved in the firm attachment of leukocytes to endothelium [11]. Both mRNA and protein levels of ICAM1 were significantly increased in animal models of DN with T1DM and T2DM $[12,13]$. Therefore, the ICAM1 gene is a strong positional and biological candidate for the susceptibility to the development of T1DM, T2DM, and DN.

Genetic association studies involving a common non-synonymous single nucleotide polymorphism (SNP) of ICAM1 (rs5498 E469K) in T1DM patients have been reported [14, 15]. Guja et al. first demonstrated that

(C) The Author(s). 2018 Open Access This article is distributed under the terms of the Creative Commons Attribution 4.0 International License (http://creativecommons.org/licenses/by/4.0/), which permits unrestricted use, distribution, and 
transmission of the G allele of SNP K469E (A/G) was increased in Romanian T1DM families [16]. Furthermore, a case-control study conducted by Ma et al. $[17,18]$ reported that the rs5498 E469K (A/G) in the ICAM1 gene might be associated with T1DM-DN in GoKinD and Swedish Caucasians. Besides, Chen et al. revealed that the 469G allele might be a susceptibility factor for T2DM with DN in Zhuang populations in the northern regions of China [19]. However, Wang et al. found that the frequency of AA genotype of E469K was significantly increased in T2DM Chinese with DN [20]. Ren et al. also reported that rs5498A allele of SNP rs5498 was associated with T2DM-DN in Chinese [21].

Due to limited sample sizes and inconsistent results of individual studies, this meta-analysis aimed to systematically evaluate the genetic association between rs5498 E469K and DN susceptibility.

\section{Methods}

\section{Literature search strategy}

This meta-analysis followed the Cochrane Collaboration definition and PRISMA 2009 guidelines for meta-analysis and systematic review [22]. To identify eligible studies, we systematically searched PubMed, Embase, the Cochrane Library and Chinese National Knowledge Infrastructure (CNKI) databases. The keywords used for search were as follows: "intercellular adhesion molecule-1 or ICAM-1" and "polymorphism OR variant" and "diabetic nephropathy or DN". No limitations on language and publication year was detected. The last search was updated on October 15, 2017. Furthermore, references of all relevant studies were retrieved to identify additional eligible studies.

\section{Inclusion/exclusion criteria}

Inclusion criteria: (1) case-control studies; (2) evaluating the association between ICAM1 rs5498 polymorphism and DN risk; (3) available genotype frequencies; (4) the genotype distribution in control groups was in the Hardy-Weinberg equilibrium (HWE). Exclusion criteria: (1) replicated studies; (2) studies in which the genotype or allele frequency could not be obtained; (3) data from meetings, case-reports, reviews or abstracts; (4) control group did not conform to HWE.

\section{Data extraction}

Two researchers (Liya Liu and Dongling He) independently extracted the data from each eligible publication, and discussed to reach a consensus in case of disagreements. For each study, the following data were reviewed and collected: First author, year of publication, ethnicity, number of cases and controls, type of DM, mean age, gender, duration time, HbA1c, Body Mass Index (BMI), creatinine, High Density Lipoprotein (HDL), Systolic blood pressure (SBP), and Diastolic blood pressure (DBP).

\section{Quality assessment}

The study quality was independently assessed by Xiaojie Yan and Ling Fang. Any discrepancies in the assessment were resolved by the third author Xiaojie Yan. The quality of each included study was assessed according to the Newcastle-Ottawa Scale (NOS) (Additional file 1: Table S1) [23]. Group selection, comparability and assessment of outcome or exposure were taken into account and given a corresponding score. Total score ranged from 0 (lowest quality) to 9 (highest quality). A study with a score of 6 or higher was selected in present meta-analysis.

\section{Statistical analysis}

Statistical analysis was conducted using the Stata software (version 12.0; Stata Corp LP, College Station, TX, USA) and RevMan software (version 5.1). The pooled ORs were performed for null versus present genotype. The statistical significance of the pooled ORs under different genetic models (allelic, recessive, additive and dominant) were determined by Z-test, and considered significant when $P<0.05$. Heterogeneity assumption was tested by the chi-square-based Q-test. An I ${ }^{2}$ value of $<50 \%$ for the Q-test indicated a lack of heterogeneity among studies, so the pooled OR estimate of each study was calculated by the fixed-effects model (the Mantel-Haenszel method). Otherwise, the random-effects model (the DerSimonian and Laird method) was used. Sensitivity analysis was performed to assess the effects of every individual study on the pooled results and the stability of results. Publication bias was assessed with funnel plots by Begg's and Egger's tests.

\section{Results}

\section{Study characteristics}

A total of 357 studies were retrieved through the literature search. A total of 14 duplicate reports were excluded. After screening the titles, abstracts, and full-texts, seven eligible studies were included in the present meta-analysis and used for data extraction $[17-21,24,25]$. A flowchart of the study selection process is shown in Fig. 1. The data of the selected studies is presented in Table 1.

\section{Meta-analysis results}

After all the extracted data were pooled, a total of 1901 cases and 1847 controls were available for ICAM1 analysis. No significant relationship between the genetic models (allelic, dominant, additive and recessive) of ICAM1 and increased risk of DN was detected $(p>0.05)$ (Fig. 2). Significant heterogeneity was observed in the total group in allelic, dominant, additive and recessive 


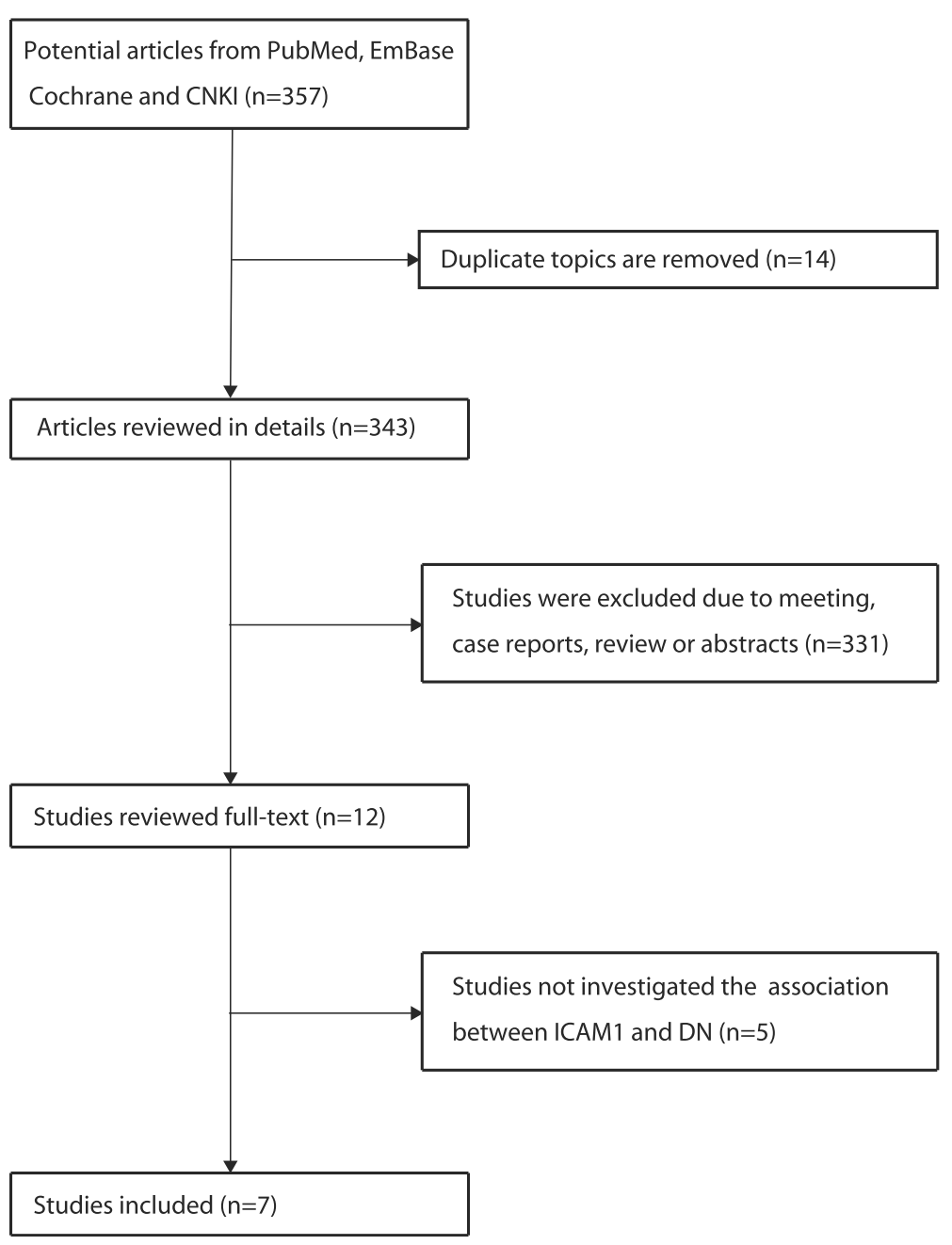

Fig. 1 PRISMA flow chart of inclusion and exclusion criteria of studies

models of ICAM1 $\left(\mathrm{I}^{2}>50 \%\right)$ (Fig. 2). Thus, subgroup analyses based on ethnicity, sample size, and type of DM were conducted. In the subgroup analyses for different countries group, the dominant model of ICAM1 showed decreased risk of $\mathrm{DN}$ among Caucasians $(\mathrm{OR}=0.80 ; 95 \% \mathrm{CI}=[0.65$, 0.99]). Also, analyses stratified by different types of DM showed a significant association of reduced risk of dominant model of ICAM1 in T1DM subgroup (OR $=0.80$; 95\% $\mathrm{CI}=[0.65,0.99], p=0.04)$, but not in T2DM subgroup (OR $=1.16 ; 95 \% \mathrm{CI}=[0.63,2.14], p=0.04)$. However, analyses stratified by sample size (sample size $>1000$ and sample size $<1000$ ) showed no significant association between allelic, dominant, additive and recessive models of ICAM1 and the risk of $\mathrm{DN}(p>0.05)$ (Table 2).

\section{Sensitivity analysis}

Sensitivity analysis was performed to determine the influence of a single study on the overall risk estimate by individually excluding each study. The ORs were not significantly altered in each adverse complication (Fig. 3).

\section{Publication bias}

The Begg's and Egger's tests were used to evaluate the publication bias. None of the funnel plots showed any evidence of publication bias (Fig. 4). The $p$ value and $\mathrm{Z}$ value for Egger's and Begg's tests showed no obvious publication bias for ICAM1 rs5498 and DN (Egger's test: allelic model: $p=0.730$; dominant model: $p=0.346$; additive model: $p=0.898$; recessive model: $p=0.738$ ) (Begg's test: allelic model: $p=0.881$; dominant model: $p=0.293$; additive model: $p=0.881$; recessive model: $p=0.881$ ).

\section{Discussion}

The present study demonstrated that the dominant model (GG + AG/AA) of ICAM1 decreased the risk of DN among Caucasian and T1DM subgroups. To the best of our knowledge, this is the first meta-analysis that 


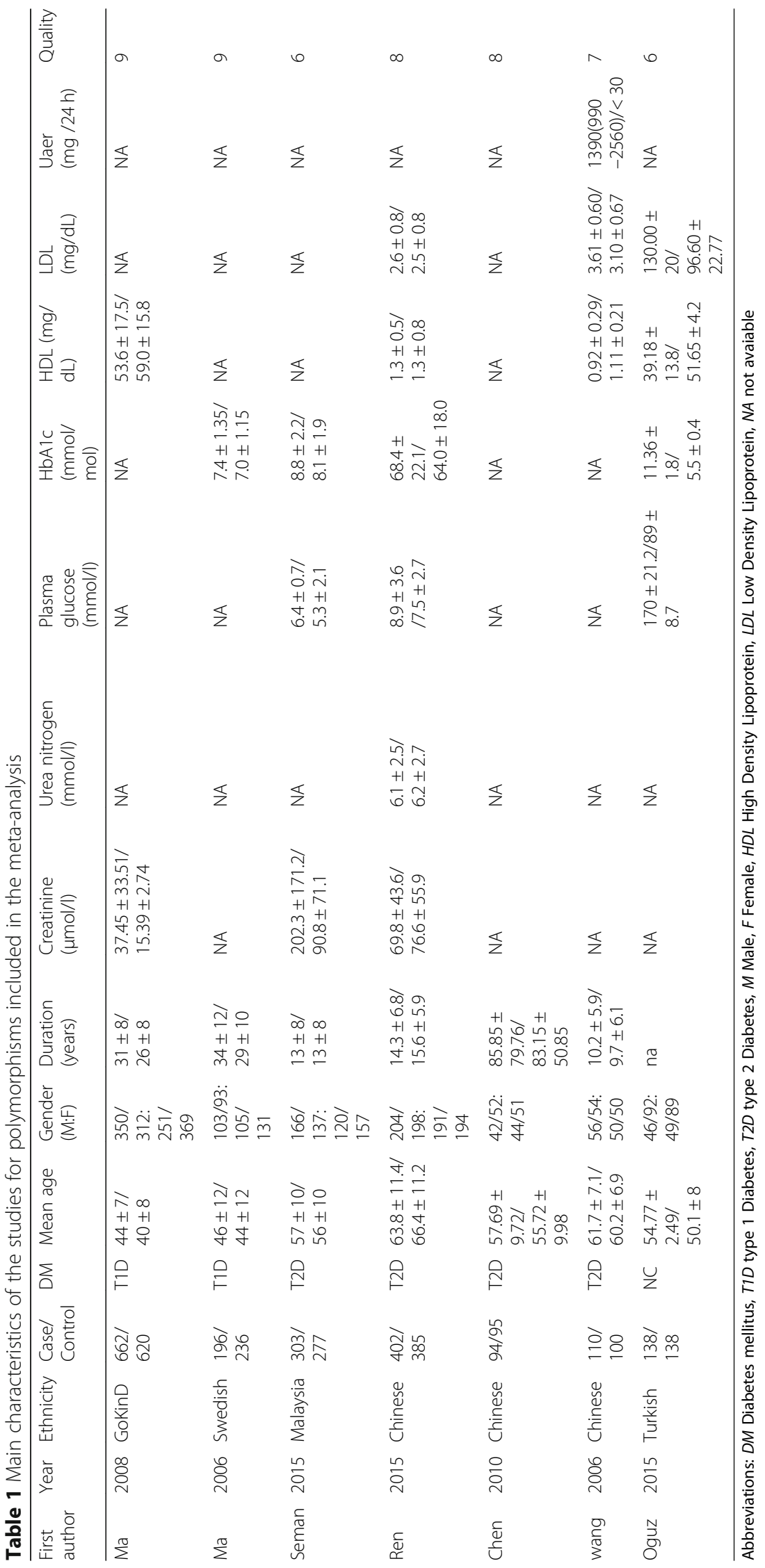




\begin{tabular}{|c|c|c|c|c|c|c|c|c|c|c|}
\hline Study or Subgroup & $\begin{array}{l}\text { Experime } \\
\text { Events }\end{array}$ & $\begin{array}{l}\text { ental } \\
\text { Total }\end{array}$ & $\begin{array}{l}\text { Contr } \\
\text { Events }\end{array}$ & $\begin{array}{l}\text { ol } \\
\text { Total }\end{array}$ & Weight & $\begin{array}{l}\text { Odds Ratio } \\
\text { M-H. Random. } 95 \% \mathrm{Cl}\end{array}$ & \multicolumn{4}{|c|}{$\begin{array}{l}\text { Odds Ratio } \\
\text { M-H. Random, } 95 \% \mathrm{Cl}\end{array}$} \\
\hline Chen 2010 & 113 & 188 & 91 & 190 & $9.9 \%$ & $1.64[1.09,2.46]$ & & & $F$ & \\
\hline Ma 2006 & 167 & 392 & 212 & 472 & $14.7 \%$ & $0.91[0.69,1.19]$ & & + & + & \\
\hline Ma 2008 & 593 & 1324 & 568 & 1240 & $19.5 \%$ & $0.96[0.82,1.12]$ & & $\Rightarrow$ & 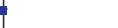 & \\
\hline Oguz 2015 & 132 & 276 & 119 & 276 & $12.2 \%$ & $1.21[0.86,1.69]$ & & & - & \\
\hline Ren 2015 & 241 & 804 & 234 & 770 & $16.9 \%$ & $0.98[0.79,1.22]$ & & + & + & \\
\hline Seman 2015 & 329 & 606 & 289 & 554 & $16.3 \%$ & $1.09[0.86,1.37]$ & & & $t$ & \\
\hline wang 2006 & 86 & 220 & 108 & 200 & $10.5 \%$ & $0.55[0.37,0.81]$ & & $\rightarrow$ & & \\
\hline Total $(95 \% \mathrm{Cl})$ & & 3810 & & 3702 & $100.0 \%$ & $1.00[0.84,1.18]$ & & $\gamma$ & 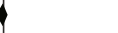 & \\
\hline Total events & 1661 & & 1621 & & & & & & & \\
\hline $\begin{array}{l}\text { Heterogeneity: } \mathrm{Tau}^{2}= \\
\text { Test for overall effect: }\end{array}$ & $\begin{array}{l}\text {.03; } \mathrm{Chi}^{2}= \\
=0.03(\mathrm{P}\end{array}$ & $\begin{array}{l}=17.42, \\
=0.98)\end{array}$ & $d f=6(P$ & $=0.00$ & $8) ; I^{2}=66 \%$ & & 0.01 & $0.1_{\text {control }}^{1}$ & $\begin{array}{cc}1 & 10 \\
\text { experimenta }\end{array}$ & 100 \\
\hline
\end{tabular}

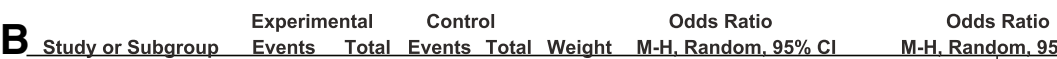

\begin{tabular}{|c|c|c|c|c|c|c|c|c|c|}
\hline & & & & & & & & & \\
\hline Chen 2010 & 81 & 94 & 69 & 95 & $9.5 \%$ & $2.35[1.12,4.92]$ & & & $=$ \\
\hline Ma 2006 & 137 & 196 & 184 & 236 & $16.0 \%$ & $0.66[0.43,1.01]$ & & & \\
\hline Ma 2008 & 452 & 662 & 447 & 620 & $21.3 \%$ & $0.83[0.66,1.06]$ & & & \\
\hline Oguz 2015 & 99 & 138 & 97 & 138 & $13.8 \%$ & $1.07[0.64,1.81]$ & & & \\
\hline Ren 2015 & 175 & 402 & 193 & 385 & $20.2 \%$ & $0.77[0.58,1.02]$ & & & \\
\hline Seman 2015 & 295 & 303 & 262 & 277 & $7.6 \%$ & $2.11[0.88,5.06]$ & & & \\
\hline wang 2006 & 70 & 110 & 78 & 100 & $11.7 \%$ & $0.49[0.27,0.91]$ & & & \\
\hline Total $(95 \% \mathrm{Cl})$ & & 1905 & & 1851 & $100.0 \%$ & $0.91[0.68,1.21]$ & & & \\
\hline Total events & 1309 & & 1330 & & & & & & \\
\hline \multicolumn{7}{|c|}{$\begin{array}{l}\text { Heterogeneity: } \mathrm{Tau}^{2}=0.09 ; \mathrm{Chi}^{2}=17.11, \mathrm{df}=6(P=0.009) ; \mathrm{I}^{2}=65 \% \\
\text { Test for overall effect: } Z=0.65(P=0.52)\end{array}$} & 0.01 & 0.1 & 10 \\
\hline
\end{tabular}

C Experimental Control Odds Ratio Odds Ratio

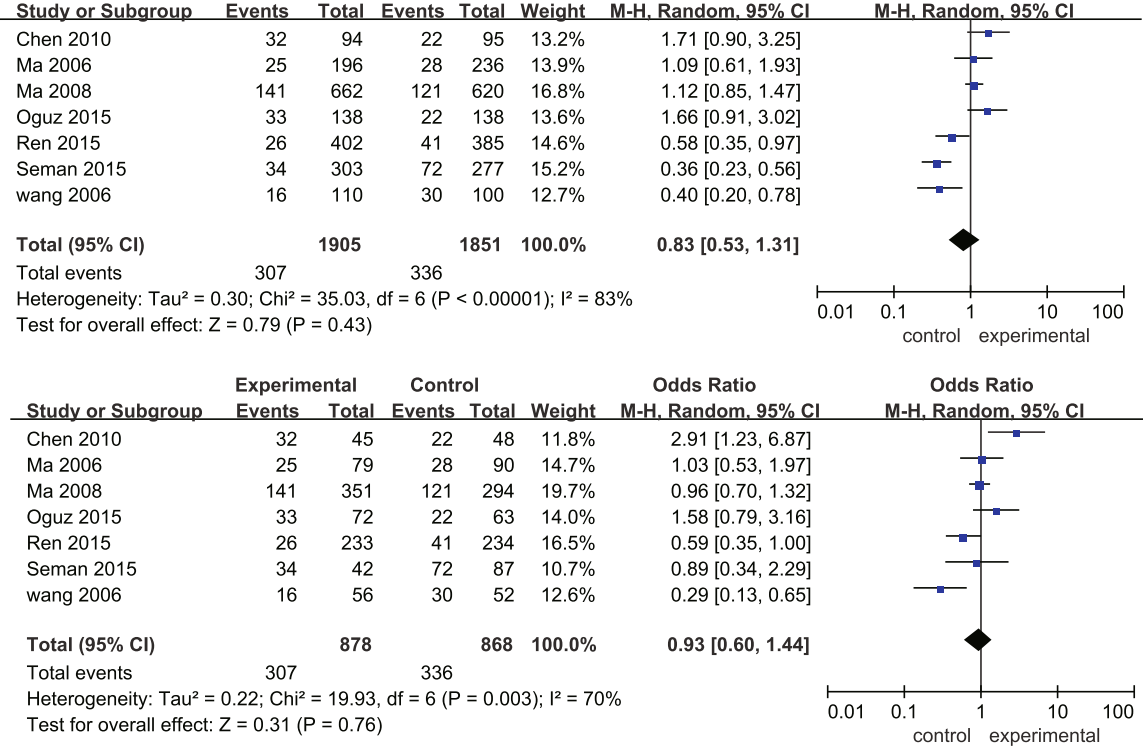

Fig. 2 Forest plots of odds ratios for the association between ICAM1 rs5498 and diabetic nephropathy. (a): allelic model; (b) dominant model; (c) recessive model; (d) additive model

assessed the genetic association between rs5498 and DN in DM patients. These findings are likely to provide a better and conclusive evaluation of ICAM1 rs5498 for the risk of DN.

Diabetes mellitus (DM) is a heterogeneous deregulation of carbohydrate metabolism, characterized by chronic hyperglycemia that results from impaired glucose metabolism and the subequent increase in blood serum glucose concentration [26, 27]. Multiple factors included metabolic, genetic and inflammatory mediators were shown to be the risk factors for DM $[28,29]$. There are three types of DM such as type 1, type 2 and gestational diabetes. Inflammation response has been considered to be a common process both in the pathology of type 1 and type 2 DM [30, 31]. Pro-inflammatory cytokines such as IL-6, IL-18, IL-1 and TNF- $\alpha$, as well as chemokines including ICAM-1, vascular cell adhesion molecule-1 (VCAM-1) and nuclear transcription factor $\kappa B(N F \kappa B)$ were reported to be significnatly increased in patients with DM [32-34].

Diabetic nephropathy (DN) is one of the microvascular complications in DM and a main cause of end-stage 
Table 2 The results of meta-analysis for ICAM1 rs5498 and diabetic nephropathy

\begin{tabular}{|c|c|c|c|c|c|c|c|c|c|c|}
\hline \multirow{2}{*}{$\begin{array}{l}\text { SNPs } \\
\text { (minor } \\
\text { allele) }\end{array}$} & \multirow{2}{*}{$\begin{array}{l}\text { Genetic } \\
\text { Model }\end{array}$} & \multirow[t]{2}{*}{ subgroup } & \multirow{2}{*}{$\begin{array}{l}\text { Number } \\
\text { of } \\
\text { studies }\end{array}$} & \multicolumn{2}{|c|}{ Numbers } & \multicolumn{2}{|c|}{ Test of association } & \multirow[t]{2}{*}{ Model } & \multicolumn{2}{|c|}{ Test of heterogeneity } \\
\hline & & & & case & $\overline{\text { control }}$ & OR[95\% Cl] & $p$-Value & & $P$ value & $I^{2}(\%)$ \\
\hline \multirow[t]{28}{*}{ rs5498 } & \multirow[t]{7}{*}{ Allelic } & total & 7 & 3802 & 3694 & $0.93[0.77,1.11]$ & 0.41 & $\mathrm{R}$ & 0.003 & 69 \\
\hline & & Asian & 5 & 2086 & 1986 & $0.93[0.69,1.25]$ & 0.64 & $\mathrm{R}$ & 0.0008 & 79 \\
\hline & & Caucasian & 2 & 1716 & 1708 & $0.94[0.82,1.08]$ & 0.40 & $\mathrm{~F}$ & 0.67 & 0 \\
\hline & & $>1000$ & 1 & 1324 & 1240 & $0.96[0.82,1.12]$ & 0.60 & NA & NA & NA \\
\hline & & $<1000$ & 6 & 2478 & 2454 & $0.92[0.73,1.17]$ & 0.50 & $\mathrm{R}$ & 0.002 & 74 \\
\hline & & T1D-DN & 2 & 1716 & 1708 & $0.94[0.82,1.08]$ & 0.40 & $\mathrm{~F}$ & 0.67 & 0 \\
\hline & & T2D-DN & 4 & 1810 & 1710 & $0.87[0.63,1.22]$ & 0.43 & $\mathrm{R}$ & 0.001 & 81 \\
\hline & \multirow[t]{7}{*}{ Dominant } & total & 7 & 1901 & 1847 & $0.96[0.73,1.27]$ & 0.76 & $\mathrm{R}$ & 0.01 & 62 \\
\hline & & Asian & 5 & 1043 & 993 & $1.12[0.71,1.76]$ & 0.63 & $\mathrm{R}$ & 0.01 & 70 \\
\hline & & Caucasian & 2 & 858 & 854 & $0.80[0.65,0.99]$ & 0.04 & $\mathrm{~F}$ & 0.55 & 0 \\
\hline & & $>1000$ & 1 & 662 & 620 & $0.83[0.66,1.06]$ & 0.14 & NA & NA & NA \\
\hline & & $<1000$ & 6 & 1239 & 1227 & $1.02[0.70,1.48]$ & 0.93 & $\mathrm{R}$ & 0.01 & 67 \\
\hline & & T1D-DN & 2 & 858 & 854 & $0.80[0.65,0.99]$ & 0.04 & $\mathrm{~F}$ & 0.55 & 0 \\
\hline & & T2D-DN & 4 & 905 & 855 & $1.16[0.63,2.14]$ & 0.64 & $\mathrm{R}$ & 0.004 & 77 \\
\hline & \multirow[t]{7}{*}{ Recessive } & total & 7 & 1901 & 1847 & $0.83[0.53,1.31]$ & 0.43 & $\mathrm{R}$ & $<0.00001$ & 83 \\
\hline & & Asian & 5 & 1043 & 993 & $0.74[0.38,1.43]$ & 0.37 & $\mathrm{R}$ & $<0.0001$ & 85 \\
\hline & & Caucasian & 2 & 858 & 854 & $1.11[0.87,1.42]$ & 0.41 & $\mathrm{~F}$ & 0.91 & 0 \\
\hline & & $>1000$ & 1 & 662 & 620 & $1.12[0.85,1.47]$ & 0.43 & NA & NA & NA \\
\hline & & $<1000$ & 6 & 1239 & 1227 & $0.79[0.45,1.38]$ & 0.40 & $\mathrm{R}$ & $<0.0001$ & 83 \\
\hline & & T1D-DN & 2 & 858 & 854 & $1.11[0.87,1.42]$ & 0.41 & $\mathrm{~F}$ & 0.91 & 0 \\
\hline & & T2D-DN & 4 & 905 & 855 & $0.61[0.31,1.17]$ & 0.13 & $\mathrm{R}$ & 0.0009 & 82 \\
\hline & \multirow[t]{7}{*}{ Additive } & total & 7 & 878 & 868 & $0.93[0.60,1.44]$ & 0.76 & $\mathrm{R}$ & 0.003 & 70 \\
\hline & & Asian & 5 & 448 & 484 & $0.92[0.44,1.92]$ & 0.82 & $\mathrm{R}$ & 0.0006 & 80 \\
\hline & & Caucasian & 2 & 166 & 149 & $0.97[0.73,1.29]$ & 0.84 & $\mathrm{~F}$ & 0.86 & 0 \\
\hline & & $>1000$ & 1 & 141 & 121 & $0.96[0.70,1.32]$ & 0.80 & NA & NA & NA \\
\hline & & $<1000$ & 6 & 527 & 574 & $0.93[0.52,1.68]$ & 0.82 & $\mathrm{R}$ & 0.001 & 75 \\
\hline & & T1D-DN & 2 & 166 & 149 & $0.97[0.73,1.29]$ & 0.84 & $\mathrm{~F}$ & 0.86 & 0 \\
\hline & & T2D-DN & 4 & 376 & 421 & $0.80[0.33,1.92]$ & 0.62 & $\mathrm{R}$ & 0.001 & 81 \\
\hline
\end{tabular}

Abbreviations: SNP single nucleotide polymorphism, T1D type 1 Diabetes, T2D type 2 Diabetes, DN diabetic nephropathy, ICAM1 intercellular adhesion molecule-1; $F$ fixed model, $R$ random model, $O R$ odds ratio, $C l$ confidence interval, NA: not available

renal disease $[35,36]$. DN occurs only in a minority of subjects with either type 1 or type 2 diabetes and seems to result from the interaction between genetic susceptibility and environmental insults [7, 37]. Many studies supporting the contribution of inflammation in diabetes involve immunosuppressive strategies that reduce renal macrophage accumulation and attenuate the development of DN [38, 39]. ICAM-1, a cell-surface protein, which was induced by inflammatory cytokines such as TNF- $\alpha$, interleukin- 1 and interferon- $\gamma$. Significantly increased renal expression of ICAM-1 in diabetic rats was deteted during diabetic renal impairment [40]. In addition, an ICAM-1 deficient $\mathrm{db} / \mathrm{db}$ mouse model of type 2 diabetes showed decreased leukocyte infiltration, reduced glomerular hypertrophy, decreased albuminuria, and decreased tubulo-interstitial fibrosis [13]. Therefore, ICAM1 may play a role in the development of DN.

In the present meta-analysis, we included studies of both T1DM and T2DM patients with and without DN. A significant association was observed between the dominant model of ICAM1 and DN in T1DM, but not in T2DM subgroup, which may indicate that ICAM1 rs5498 was a susceptible factor in T1DM as well as DN. Several groups have reported genetic association studies of ICAM1 rs5498 in T1DM. Guja et al. reported that the transmission of the G allele of SNP K469E (A/G) is increased in Romanian T1DM families [16]. Nishimura et al. showed that this K469E polymorphism is associated with adult-onset T1DM in a Japanese population [26]. However, the association of K469E polymorphism 


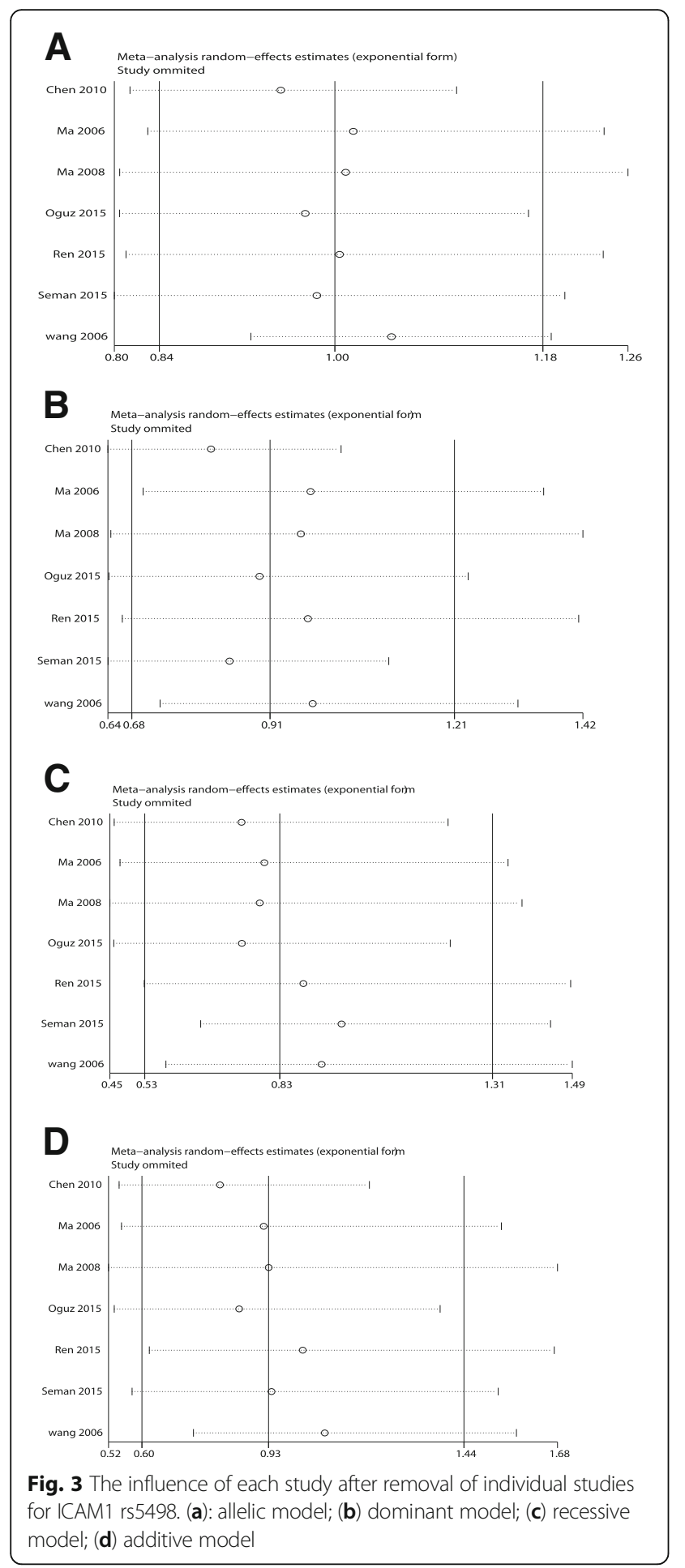

in the ICAM1 gene with T1DM was not found in Danish, Finnish, and British Caucasians [14]. The genetic association between ICAM1 and T1DM-DN was only found in studies conducted by Ma et al. in GoKinD and Swedish Caucasians with 858 cases and 856 controls, which may reduce the power to evaluate the association
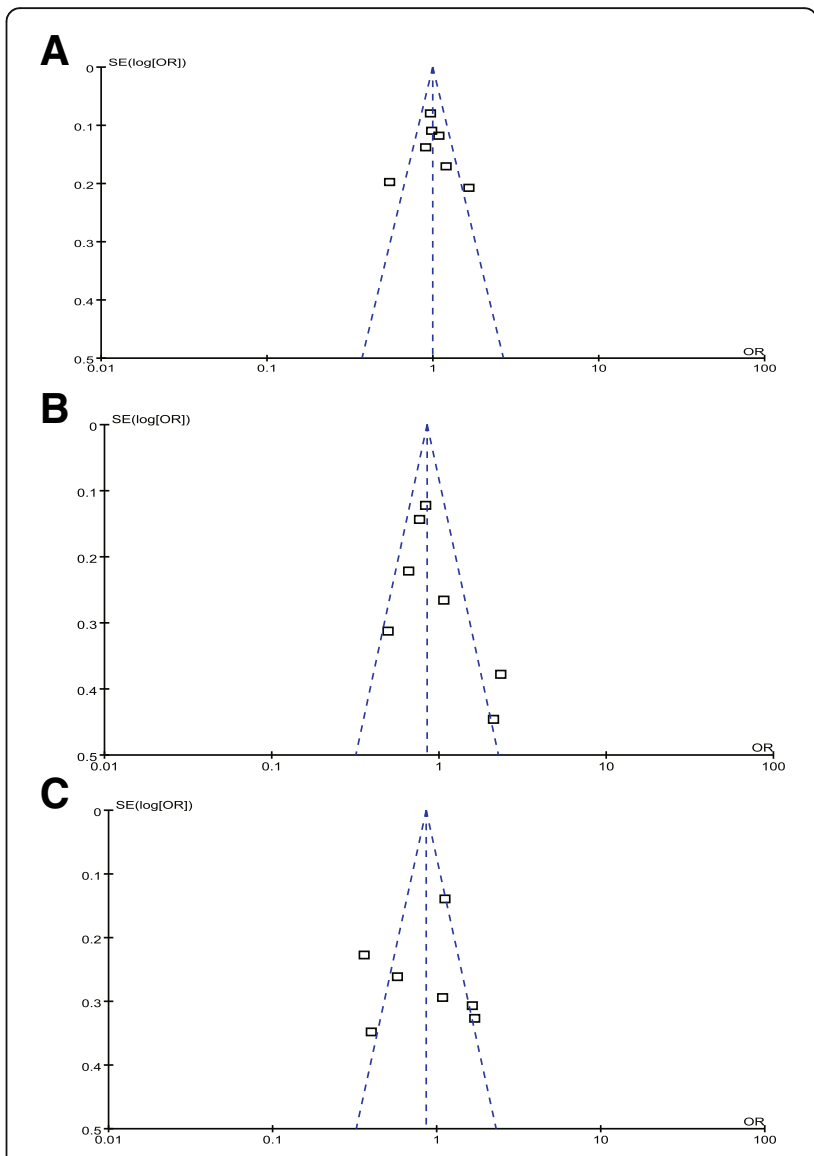

D

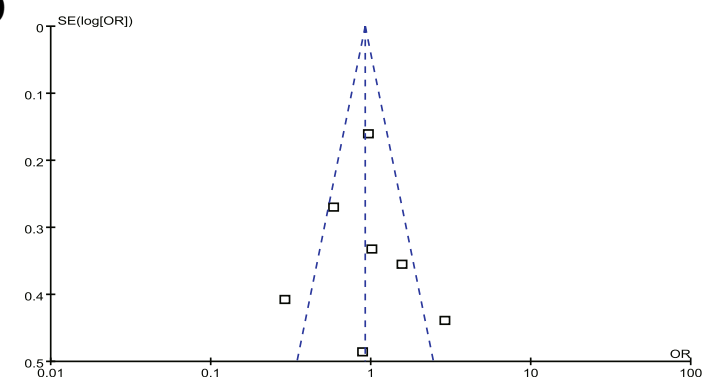

Fig. 4 Funnel plot of publication bias for the association between ICAM1 rs5498 and diabetic nephropathy. (a): allelic model; (b) dominant model; (c) recessive model; (d) additive model

due to the relatively small sample size. For T2DM-DN, four studies refer to the genetic association between ICAM1 rs5498 and T2DM-DN, while negative result was observed in the present combined analysis.

Notably, significant association was only detected in the Caucasian subgroup, but not in the Asian subgroup. Previous studies indicated that this polymorphism was found to be associated with adult-onset T1DM in Japanese patients [41], but not in Danish, Finnish and British Caucasians [14]. Different genetic backgrounds in Caucasians and Asians might contribute to this inconsistency. Among the included studies, only two studies 
$[17,18]$ reported the association between ICAM1 and DN in Caucasian population, which may have affected the real correlation of ICAM1 and DN in Caucasians. Thus, additional studies with larger cohorts are necessary.

Statistically significant heterogeneity across studies was observed in all genotype models $\left(\mathrm{I}^{2}\right.$ ranged from 62 to 95). Significant heterogeneity was also found in Asians, sample size $<1000$, and T2D subgroups in all genotype models ( $\mathrm{I}^{2}$ ranged from 67 to 97$)$. There could be several reasons for these heterogeneities. Firstly, most of these studies had small sample size. Secondly, different strategies were applied in various studies, including control source, population stratification, phenotype selection, genotyping methods, etc.

The limitations of this study should be mentioned. First, the sample size was relatively small, with most studies assessing only a few dozen patients. Large-scale case-controls would have improved the accuracy of the present findings. Secondly, DM types in the patients enrolled in this meta-analysis were somewhat different, since a particular type of DM was not targeted by our inclusion criteria. Thirdly, multiple factors can influence the development of $\mathrm{DN}$, especially the gene-gene interaction and gene-environment interaction, which were not analyzed due to lack of sufficient data. Lastly, we only included studies with two ethnicities. Multiple ethnicity groups need to be assessed in the future to confirm these findings.

\section{Conclusion}

ICAM1 rs5498 may contribute to the susceptibility to DN in dominant model in Caucasians and T1DM patients. More well-designed studies with large sample size and different ethnicities are necessary to confirm this finding.

\section{Additional file}

Additional file 1: Table S1. Newcastle-Ottawa scale (NOS) for quality assessment of included studies. (DOC $32 \mathrm{~kb}$ )

\section{Abbreviations}

BMI: Body Mass Index; CNKI: Chinese National Knowledge Infrastructure; DBP: Diastolic blood pressure; DM: Diabetes mellitus; DN: diabetic nephropathy; ESRD: end-stage renal disease; HDL: High Density Lipoprotein; HWE: Hardy-Weinberg equilibrium; ICAM1: intercellular adhesion molecule 1; NOS: Newcastle-Ottawa Scale; SBP: Systolic blood pressure; SNP: single nucleotide polymorphism; T1DM: type 1 DM; T2DM: type 2 DM

\section{Acknowledgements}

None.

\section{Funding}

None.

\section{Availability of data and materia}

The data set supporting the results of this article are included within the article.

\section{Authors' contributions}

YXJ conceived and coordinated the study, designed, performed and analyzed the experiments, wrote the paper. HDL and FL carried out the data collection, data analysis, and revised the paper. All authors reviewed the results and approved the final version of the manuscript.

Ethics approval and consent to participate

Not applicable.

\section{Consent for publication}

Not applicable.

\section{Competing interests}

The authors declare that they have no conflict of interest.

\section{Publisher's Note}

Springer Nature remains neutral with regard to jurisdictional claims in published maps and institutional affiliations.

\section{Author details}

${ }^{1}$ Department of Pharmacy, Shenzhen Hospital, Southern Medical University, Shenzhen 518000, Guangdong, China. 'Department of Nephrology, The Eight Affiliated Hospital, SUNYAT-SEN University, Shenzhen, Guangzhou 518033, China. ${ }^{3}$ Department of Endocrinology, Shenzhen Hospital, Southern Medical University, No. 1333, New Lake Road, Baoan District, Shenzhen 518000, Guangdong, China.

Received: 14 June 2018 Accepted: 20 November 2018

Published online: 26 December 2018

References

1. Heerspink HJ, de Zeeuw D. The kidney in type 2 diabetes therapy. Rev Diabet Stud. 2011:8:392-402.

2. Cornell S, Dorsey VJ. Diabetes pharmacotherapy in 2012: considerations in medication selection. Postgrad Med. 2012;124:84-94.

3. Marshall SM. Recent advances in diabetic nephropathy: Pergamon press; 2004

4. Kaul K, Hodgkinson A, Tarr JM, Kohner EM, Chibber R. Is inflammation a common retinal-renal-nerve pathogenic link in diabetes? Curr Diabetes Rev. 2010;6:294-303

5. Navarro-Gonzalez JF, Mora-Fernandez C, Muros de Fuentes M, Garcia-Perez J. Inflammatory molecules and pathways in the pathogenesis of diabetic nephropathy. Nat Rev Nephrol. 2011;7:327-40.

6. Thomas MC, Groop PH. New approaches to the treatment of nephropathy in diabetes. Expert Opin Investig Drugs. 2011;20:1057-71.

7. Brennan E, McEvoy C, Sadlier D, Godson C, Martin F. The genetics of diabetic nephropathy. Genes (Basel). 2013;4:596-619.

8. Gonzalez-Bulnes A, Ovilo C. Genetic basis, nutritional challenges and adaptive responses in the prenatal origin of obesity and type-2 diabetes. Curr Diabetes Rev. 2012;8:144-54.

9. Morahan $\mathrm{G}$. Insights into type 1 diabetes provided by genetic analyses. Curr Opin Endocrinol Diabetes Obes. 2012;19:263-70.

10. Cox NJ, Wapelhorst B, Morrison VA, Johnson L, Pinchuk L, Spielman RS, et al. Seven regions of the genome show evidence of linkage to type 1 diabetes in a consensus analysis of 767 multiplex families. Am J Hum Genet. 2001;69: 820-30

11. Springer TA. Adhesion receptors of the immune system. Nature. 1990;346: 425-34

12. Qi XM, Wu GZ, Wu YG, Lin H, Shen JJ, Lin SY. Renoprotective effect of breviscapine through suppression of renal macrophage recruitment in streptozotocin-induced diabetic rats. Nephron Exp Nephrol. 2006;104: e147-57.

13. Chow FY, Nikolic-Paterson DJ, Ozols E, Atkins RC, Tesch GH. Intercellular adhesion molecule-1 deficiency is protective against nephropathy in type 2 diabetic db/db mice. J Am Soc Nephrol. 2005;16:1711-22.

14. Kristiansen OP, Nolsoe RL, Holst H, Reker S, Larsen ZM, Johannesen J, et al. The intercellular adhesion molecule-1 K469E polymorphism in type 1 diabetes. Immunogenetics. 2000:52:107-11.

15. Nejentsev S, Laine AP, Simell O, Ilonen J. Intercellular adhesion molecule-1 (ICAM-1) K469E polymorphism: no association with type 1 diabetes among Finns. Tissue Antigens. 2000;55:568-70. 
16. Guja C, Todd J, Welsh K, Marshall S, lonescu-Tirgoviste C. Increased transmission of intercellular adhesion-molecule-1, 469E allele in type 1 Romanian diabetic families. Diabetologia. 1999;42:327.

17. Ma J, Mollsten A, Prazny M, Falhammar H, Brismar K, Dahlquist G, et al. Genetic influences of the intercellular adhesion molecule 1 (ICAM-1) gene polymorphisms in development of type 1 diabetes and diabetic nephropathy. Diabet Med. 2006;23:1093-9.

18. Ma J, Zhang D, Brismar K, Efendic S, Gu HF. Evaluation of the association between the common E469K polymorphism in the ICAM-1 gene and diabetic nephropathy among type 1 diabetic patients in GoKinD population. Bmc Medical Genetics. 2008;9:47.

19. Chen JN, Xiao-Li LI, Wei JZ. The correlation of the ICAM-1 gene and type I diabetic nephropathy in Zhuang populations in the northern regions of Guilin. Acta Medicinae Sinica. 2010.

20. Wang YN, Liu HL, Sun Y. Association of intercellular adhesion molecule-1 gene K469E polymorphism to type 2 diabetic nephropathy. Chinese Journal of Nephrology. 2006;22:201-4.

21. Ross JS, Badve S, Wang K, Sheehan CE, Boguniewicz AB, Otto GA, et al. Genomic profiling of advanced-stage, metaplastic breast carcinoma by next-generation sequencing reveals frequent, targetable genomic abnormalities and potential new treatment options. Arch Pathol Lab Med. 2015;139:642-9.

22. Boccia S. PRISMA: an attempt to improve standards for reporting systematic review and meta-analysis. Epidemiology Biostatistics \& Public Health. 2009;6: E382.

23. Wells GA, Shea BJ, O'Connell D, Peterson J, Welch V, Losos M, et al. The Newcastle-Ottawa Scale (NOS) for Assessing the Quality of NonRandomized Studies in Meta-Analysis. Applied Engineering in Agriculture. 2014;18:págs. 727-734

24. Oguz E, Tabur S, Akbas H, Korkmaz H, Torun A, Dilmec F, et al. Investigation of the role of ICAM-1 E469K and E-selectin S128R polymorphisms in diabetic neuropathy. 2015.

25. Abu Seman N, Anderstam B, Wan Mohamud WN, Ostenson CG, Brismar K, Gu HF. Genetic, epigenetic and protein analyses of intercellular adhesion molecule 1 in Malaysian subjects with type 2 diabetes and diabetic nephropathy. J Diabetes Complicat. 2015;29:1234-9.

26. Wong YC. Need of integrated dietary therapy for persons with diabetes mellitus and "unhealthy" body constitution presentations. J Integr Med. 2016;14:255-68

27. Chakraborty R, Roy S, Mandal V. Assessment of traditional knowledge of the antidiabetic plants of Darjeeling and Sikkim Himalayas in the context of recent phytochemical and pharmacological advances. J Integr Med. 2016;14: 336-58.

28. Hamman RF. Genetic and environmental determinants of non-insulindependent diabetes mellitus (NIDDM). Diabetes Metab Rev. 1992:8:287-338.

29. Pratley RE. Gene-environment interactions in the pathogenesis of type 2 diabetes mellitus: lessons learned from the Pima Indians. Proc Nutr Soc. 1998;57:175-81.

30. Libby P, Plutzky J. Inflammation in diabetes mellitus: role of peroxisome proliferator-activated receptor-alpha and peroxisome proliferator-activated receptor-gamma agonists. Am J Cardiol. 2007;99:27B-40B.

31. van den Oever IA, Raterman HG, Nurmohamed MT, Simsek S. Endothelial dysfunction, inflammation, and apoptosis in diabetes mellitus. Mediat Inflamm. 2010;2010:792393.

32. Esposito K, Nappo F, Marfella R, Giugliano G, Giugliano F, Ciotola M, et al. Inflammatory cytokine concentrations are acutely increased by hyperglycemia in humans: role of oxidative stress. Circulation. 2002;106: 2067-72.

33. Foss NT, Foss-Freitas MC, Ferreira MA, Cardili RN, Barbosa CM, Foss MC. Impaired cytokine production by peripheral blood mononuclear cells in type 1 diabetic patients. Diabetes Metab. 2007;33:439-43.

34. Navarro-Gonzalez JF, Muros M, Mora-Fernandez C, Herrera H, Meneses B, Garcia J. Pentoxifylline for renoprotection in diabetic nephropathy: the PREDIAN study. Rationale and basal results. J Diabetes Complicat. 2011;25: 314-9.

35. Duran-Salgado MB, Rubio-Guerra AF. Diabetic nephropathy and inflammation. World J Diabetes. 2014;5:393-8.

36. Motavallian A, Andalib S, Vaseghi G, Mirmohammad-Sadeghi H, Amini M. Association between PRO12ALA polymorphism of the PPAR-gamma2 gene and type 2 diabetes mellitus in Iranian patients. Indian J Hum Genet. 2013; 19:239-44.
37. Conway BR, Maxwell AP. Genetics of diabetic nephropathy: are there clues to the understanding of common kidney diseases? Nephron Clin Pract. 2009;112:c213-21

38. Wu Y, Dong J, Yuan L, Liang C, Ren K, Zhang W, et al. Nephrin and podocin loss is prevented by mycophenolate mofetil in early experimental diabetic nephropathy. Cytokine. 2008:44:85-91.

39. Wittmann S, Daniel C, Stief A, Vogelbacher R, Amann K, Hugo C. Long-term treatment of sirolimus but not cyclosporine ameliorates diabetic nephropathy in the rat. Transplantation. 2009;87:1290-9.

40. Elsherbiny NM, Abd El Galil KH, Gabr MM, Al-Gayyar MM, Eissa LA, ElShishtawy MM. Reno-protective effect of NECA in diabetic nephropathy: implication of IL-18 and ICAM-1. Eur Cytokine Netw. 2012;23:78-86.

41. Nishimura M, Obayashi H, Maruya E, Ohta M, Tegoshi H, Fukui M, et al. Association between type 1 diabetes age-at-onset and intercellular adhesion molecule-1 (ICAM-1) gene polymorphism. Hum Immunol. 2000;61: 507-10.

\section{Ready to submit your research? Choose BMC and benefit from:}

- fast, convenient online submission

- thorough peer review by experienced researchers in your field

- rapid publication on acceptance

- support for research data, including large and complex data types

- gold Open Access which fosters wider collaboration and increased citations

- maximum visibility for your research: over $100 \mathrm{M}$ website views per year

At BMC, research is always in progress.

Learn more biomedcentral.com/submissions 